\title{
The Integration of Media Technology and the Change of Education (IMTCE) - A Study of Model of the Impact of Media Technology on Education
}

\author{
Xiaochuan Zhu
}

\begin{abstract}
Education can not be separated from media technology. The change of education is closely related to the change of media technology. But the change of media technology does not necessarily bring about the change of education. To promote the effective use of media technology in the field of education requires a thorough understanding of the role of media technology and education. By referring to the process of social change by changing technology and combining the characteristics of education, a model of media technology influencing education is constructed and applied in case analysis. It is found that the influence of media technology on education is a cycle of solving the two problems, namely, the contradiction between supply and demand of education and the function playing of media technology. This process starts with the needs of educational change, and finally realizes the development of education through changing the media technology and playing the function of media technology.
\end{abstract}

Index Terms-Media technology, educational change, instruction system, model construction, integrate into.

\section{INTRODUCTION}

Since modern times, change has gradually become an important theme of educational development [1]. The phenomena such as the emergence of distance education, putting forward the idea of lifelong education, popularizing compulsory education system, network education and individualized education going from the edge to the mainstream et al., reveal the oscillations experienced by education from tradition to Modernity.

Oscillation is a qualitative change, and change is a man-made oscillation. Educational change is a major adjustment of educational factors and structure relationship caused by human beings under the guidance of the goal. Historically, every change in education has been linked to changes in media technology. The appearance of characters separated education from society. The advent of print media has rapidly expanded the scale of education. The appearance of multimedia computer has improved the interactive form of instruction. The advent of Internet technology has made ubiquitous learning possible.

The contribution of technology to educational change has made people magnify the role of technology, which attracts

Manuscript received September 13, 2017; revised November 23, 2017. Xiaochuan Zhu is with School of Educational Technology, Faculty of Education, Beijing Normal University, Beijing, China (e-mail: 573398661@qq.com). more and more technical media pouring into education and makes people get expectation for future educational change. From Edison to Plessey, from the movie teaching to the individual teaching based on machines, expectations haven't not completely come into reality [2]. This shows that technological change does not necessarily lead to change in education. It is necessary to further explore the logical process of media technology influencing education.

\section{The ImPaCt OF TeChNOLOGiCAL Change ON SOCial CHANGE}

Because of the similarity in functional performance, the influence of media technology in education can refer to the impact of technological change on society, which makes it possible that the mechanism of impact of technological change on social media explains the mechanism of the effect of technology on education.

With the industrial revolution as an example, along with the invention of the machine, machine manufacturing took the place of the hand-made manufacturing so that the production efficiency was improved greatly and economies of scale led to a rapid decline in price. The handicraft workshops was forced to be left in the big machine production, which means Society has entered the industrial age from the agricultural age [3].

The basic logic of the reform process is that technical improvement leads to invention of machine, and the invention of machine brings a new mode of production, and the new mode of production leads to the scale benefits, and the scale benefits form competitive advantage, which result in the social transformation. The question is how the process from technological improvement to production change happens? If technology does not necessarily bring about changes in the mode of production, why should people make technical improvements?

Improvement means that there are problems with the original technology, that is, there is a gap between the original technical function and people's expectations. Due to manpower constraints, the output of handicraft industry is difficult to meet the demand of capital for profits so that technological change in the dimension of production efficiency occurs. Machines have been invented, but the function of machines has not been exploited in hand shops. As a result, people further improve their work organization model and eventually form a man-machine matching mode of production, as shown in Fig. 1.

Fig. 1 shows the process of technological change affecting 
the mode of production, and the dashed arrow in the diagram indicates a change in the mode of production. This transformation includes two improvement processes, one is the improvement of technical function, and the other is the improvement of the organization of personnel working based on the function of technology. Improving technology function mainly refers to enhancing the function of technology in the dimension of the demand, which cause the contradictions between the technology function and the way of working that is solved through improving people's work organization. The man-machine matching method which is left by the improving process mentioned above is called the new mode of production.

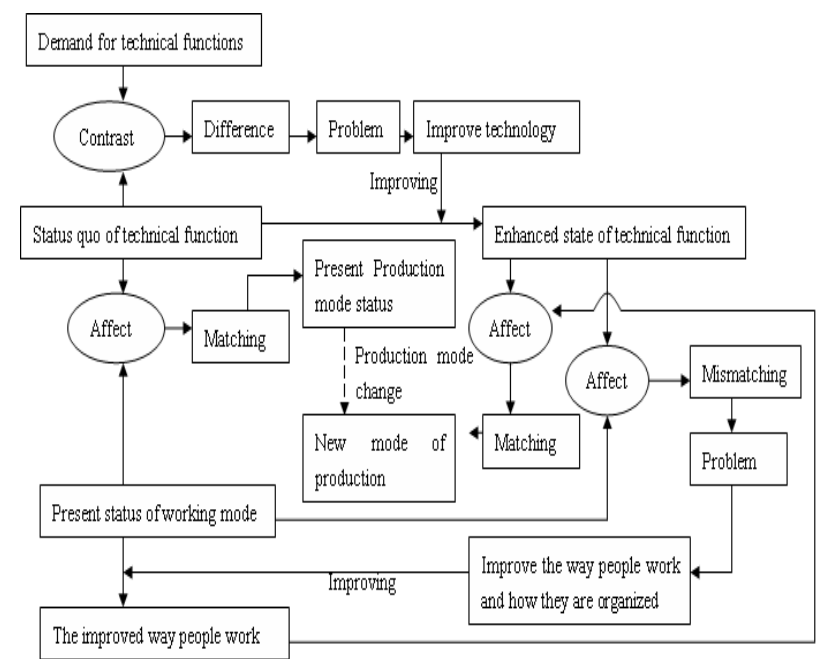

Fig. 1. Schematic diagram of technological change to promote production mode change.

The above two improvements are shown in Fig. 1 as follows: On the left hand side of Fig. 1, it can be seen that the matching between the status of the technical function and the way people work is realized by interaction and a stable mode of production is formed. At the top of Fig. 1, it can be seen that people have new requirements on the technical function. The expectations which the new requirements point to have something different from the status of the function of technology by comparison, leading to problems which can only be solved through improving the technologies, improving the function of the technologies in the demand dimensions. As you can see at the top of Fig. 1, this improved activity causes the actual state of the technical capabilities to evolve into an enhanced state. The enhanced state of technological function interacts with the way people work in production, thus causing problems, which can be shown on that the augmented state, which is manifested as technical function, is not fully presented in practice. The reason is that the way people work and how they are organized does not fit in with the new technological functions. At the bottom of Fig. 1 , it can be seen that the improved way people work and how they are organized matches the enhanced state of technical function in the end after interaction and adjustment. Then a new mode of production is formed. Thus, the improvement of technology is only a part of the change in the mode of production under the new demand driven, not the whole. Only when technological improvements lead to improvements in the way people work and organize, can the innovation of the mode of production be completed.

\section{Constructing Model of Media Technology INFLUENCING EDUCATION}

In analogy to the impact of technological change on society, the impact of media technology on education can also be achieved through the impact of teaching methods. As an element of the instruction system, media technology connects teachers and students, and its function changes directly affect the changes in the relationship between teaching and learning. If keeping the dynamic balance of the three as the premise, and taking the change of media technology as the reference, it will inevitably lead to changes in the entire instruction system [4].

As a subsystem of the society, the education system's function is to meet the social demand for education, which includes the whole social demand of education in the macro level, also includes individual social demand for education in the micro level. These demands are met through forcing the instruction system to enhancing function without end. When the change of media technology caters to the demand of society for education, its change becomes the reference of other factors' change, and causes other factors to change with it. Otherwise, changes in media technology will become a disturbance to the operation of the teaching system, not only can not promote the instruction system to the social expectations of change, but also hinder the realization of teaching objectives, resulting in decreased quality of instruction.

If the function of the media is used as the prerequisite for the reconstruction of the instruction system, the reconstruction of instruction system can make the instruction system get more functions in the dimension of social needs. As a result, a model of media technology influencing education can be constructed, as shown in Fig. 2.

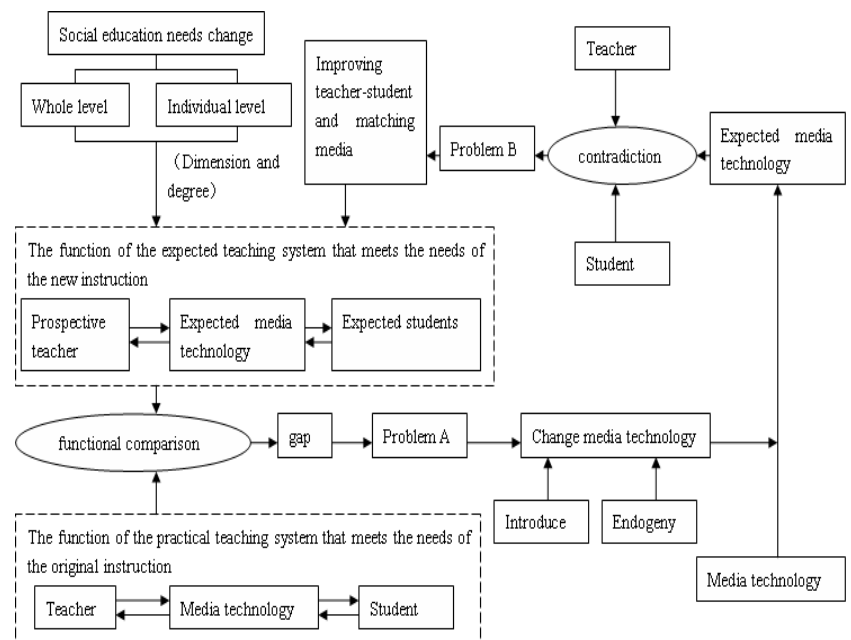

Fig. 2. Model diagram of media technology influencing education.

In Fig. 2, what is in the dashed box is the instruction system including three core elements of teachers, students and media technology. The instruction system in the dashed box in the middle of the Fig. 2 indicates the desired instruction system, which shows the expected function in people's minds. The instruction system in the dashed box at the bottom of the Fig. 2 shows the actual teaching system, which presents a realistic function. Above the dashed frame which encloses the expectations instruction system is the 
social education demand changes which lead to generating the instruction system. The changes not only include the ones in the overall level of demand, but also include the ones in the individual level of demand, shown in the corresponding dimension and degree. After being compared in function, the contents in the two dashed frame are different, which causes the results are different, leading to the problem of $\mathrm{A}$, which means that the status of media technology fails to meet the expectations of media technology. In order to solve this problem, media technology needs to be improved either by introducing or by generating. By improving media technology, the status quo of media technology has evolved into the expectation of media technology. The top right of Fig. 2 shows there is a contradiction between the expected media technology and the elements of teacher and student in the current instruction system, which lead to problems of B, that is the function of the improved technology is difficult to fully show the expected result because the relation between the expected media technology and the elements of teacher and student in the current instruction system is Out of harmony. At the top of Fig. 2, it can be seen that the solution to the problem $\mathrm{B}$ requires the improvement of the elements of teachers and students and their relationship with each other so that it can match the improved media to achieve the function of the desired instruction system.

From this it can be seen that the impact of media technology on education needs to go through two problem-solving processes. Problem A is the problem about the reform of the media and problem $B$ is the problem about the reconstruction of the instruction system based on the change in the media. The process of solving these two problems constitutes a logical loop. Problem A is triggered by the contradiction between the social demand for education and the status quo of education, pointing to the balance between the supply and demand of education. The problem B is triggered by the solution of the problem $\mathrm{A}$, and the problem A can only be resolved eventually if the problem $B$ is answered.

In Fig. 2, the logical starting point of media technology's impact on education is not the change of media technology, but the change of society's demand for education. This change leads to the change of instruction demand in a certain dimension and degree, and forms new instruction needs. The new instruction needs will inevitably require the formation of an instruction system that meets the expectations of the needs, including expected teachers, expected media technology and expected students. Accordingly, the original instruction needs correspond to the reality instruction system. Through the function comparison, the gap between the expected instruction system and the actual instruction system is formed, which leads to problem A. In order to narrow the gap, it is needed to change media technology at first, changing the existing media technology into the desired media technology. The improvement of media technology breaks the balance of the original instruction system, which leads to contradictions with teachers and students so that the problem B is caused. In order to achieve the desired function of the expected media technology, it is necessary to adjust the relationship between the three aspects of teachers, students and media technology, and achieve the expected dynamic balance at a new level.
As a result, changes in media technology are a key factor in education change, but not a decisive factor, because media technology change comes from the process of solving the problem A.

\section{Case Analysis}

In order to test the rationality of media technology affecting the educational model, the following two cases are explained and analyzed.

\section{A. Media Technology Transformation and the Emergence and Development of Distance Education}

Distance education refers to the form of education in which teachers and students are separated by time and space [5]. Because of the separation of teachers and students in time and space, distance education and media technology has a closer relationship than the traditional face-to-face education. Since its birth, distance education has experienced three stages, such as correspondence education, radio and television education, and online education et al., and develops to a higher level. Accordingly, media technology has also undergone the evolution of the three generation of print media, radio and television media and computer network media [6], And extends to the large data, cloud computing and intelligent media and other fields.

Although distance education originated in modern times, the phenomenon of distance education was not absent before modern times. In the spring and Autumn period of China, Confucius had adopted the method of teaching some disciples first, and then these disciples was asked to teach other disciples [7]. Although this is conducive to expanding the scale of education, but the effect is very limited. In modern times, under the impact of industrial revolution and democratic thought, people began to seek the expansion of scale in the field of education. The printing media that cater to this demand have been introduced into education, and the teachers and students are separated from time and space by means of correspondence, but it has also caused the contradiction between scale and quality control. This led people to further explore the distance instruction mode based on the print media, causing the traditional face-to-face education reform, separating distance education form.

Although correspondence education has expanded the educational scale to a certain extent, due to the defects of information representation, a large amount of visualized information has been lost, and the non real time nature of information transmission has also increased the learners' learning difficulties. The need for improved quality of education looks for more real-time and less easily distorted media on information representation and delivery, which has led to the introduction of radio and television media into distance education. The enhancement of the media function causes the contradiction between the original teaching methods and the new media functional requirements, which promotes the exploration of the law of Distance Education under the new media technology conditions.

Compared with the traditional face-to-face education, the second generation of distance education based on the radio and television media technology is still insufficient in the 
interactivity. The awakening of people's subjective consciousness brought about by the democratization movement makes instruction no longer regarded as a one-way instruction by teachers to students, but as a two-way interaction between teachers and students on the basis of equality. Radio and television media are difficult to adapt to such requirements, and new problems lead to the introduction of new media technology, thus triggering the existing crisis of the original form of distance education. On the basis of exerting the function of new media technology, the solution of crisis leads the distance education to a new form. Distance education is becoming more and more open and more and more tolerant. It gradually constructs the realistic foundation of lifelong education in the process of mutual promotion with media technology again and again.

From the case of media technology transformation and the emergence and development of distance education, the traditional instruction method is in a stable state after the historical baptism, and is in harmony with the social environment. At this point, even though new media technologies have emerged in society, it is difficult to attract the attention of the subject in the field of instruction system. The development of society has changed people's demand for instruction system which began with the expansion of the scale dimension and needs to extend the teaching coverage of teachers. The primary factor hindering the realization of this demand is the limitation of media technology, so changing media technology is the first step in changing the instruction system. In the spring and autumn period, Confucius took the students directly taught as a medium to expand the scale, through the way students taught students, but the scope was very limited. The mass communication function of printed media enables instruction to be separated in time and space, which leads to the rapid expansion of scale. Before long, Radio and television media have further expanded the scope of teaching communication. The change of media technology in different periods leads to the continuous upgrading of scale in the process of emergence and development of distance education, which makes it possible to alleviate the contradiction between supply and demand in scale of instruction system. That improvement of media technology does not necessarily guarantee the improvement of the functions can be fully realized in the real conditions, because other factors remain unchanged, improvements in media technology may lead to problems in other dimensions, such as the quality dimension, which in turn limits the full function of media technology. If people want to ensure the full function of the media technology and that the quality does not decline, the only thing to do is to change the relationship between media technology and other factors in the instruction system, which will inevitably lead to the whole instruction system reform and the formation of a new form of distance education. After the problem of scale is solved, the society's demand for distance education points to individualization, emphasizing on equal two-way interaction between teachers and students, which requires upgrading the media's capabilities in the interactive dimension, then, based on the interactive function of media technology, the relation between media technology and other teaching elements is adjusted and a new form of Distance Education is formed. In this way, distance education is promoted to develop in the desired dimension.

Thus, improvement of media technology does not directly bring the change of distance education. Only when the social demand for distance education is pushed forward, can the media technology improvement bring about the change of the whole instruction system, so as to promote education reform.

\section{B. The Change Media Technology and the Evolution of Learning Style}

Learning is the ordered and persistent self change that learners make by interacting with learning objects in a certain way based on certain purposes [8]. It is worth noting that the learning objects are not all visible and tangible entities, and neither the learners nor the subjects can interact directly with each other. This requires an intermediary. The learner, the intermediary and the learning object form the interactive relation, thus form the learning system, and its way of operation is the way of learning.

Life experience tells people that every thing needs the support of corresponding assistant work. For example, the use of computers, if you want to carry out word processing, first of all ,you need to start the computer operating system software, and then run text editing and processing software, enter the text editing interface, until then you can carry out word processing. Similarly, the learners also need the auxiliary work process which is carried out by media technology. On the one hand, the media technology is used to support learners to access learning objects. On the other hand, it is used to support learners to interact better with learning objects.

In the period of mainstream of print media technology, learning is primarily through contacting with physical objects or books. Learners need to look for objects or books and observe, manipulate physical objects, or read books in a certain time and space. With the development of society and the rapid expansion of knowledge, it is no longer difficult for learner to contact knowledge. The difficult point transfers to treatment and screening of a large amount of information, and changes to how to quickly find the real learning object which learners really need to learn, which lead to the influx of information technology. With the help of information technology, knowledge is ordered and visualized, and learners no longer need to process a large amount of information at a shallow level, but instead deal with the learning objects directly at a deep level. Learning styles are traditionally based on acceptance and understanding of knowledge, and turning to knowledge innovation based on information technology.

Learners always expect to engage in activities that are consistent with their learning goals and do not want to spend a lot of time and energy in finding the learning objects. This contradiction promotes the continuous improvement of media technology, and its role changes from supporting, seeking and dealing with learning objects to creating a intelligent learning environment. The learner's needs are perceived and the learning objects are pushed rapidly to the learner. Based on this, intelligent learning becomes a new way of learning for learners.

The development of network technology connects people's 
wisdom and creates new space-time and information organization mode. This provides a new platform for learners and enables learners to form a new understanding of learning under network conditions. Learning is no longer an individual act, but a manifestation of the interaction of many individuals. Among them, there is a learning theory named connectivism which has the relatively large impact [9]. This makes the learning mode of Unicom gradually become an important branch of learning methods under the network conditions.

People expect to learn with the freedom of time and space. The expectation of freedom of time and space, the contradiction between expectation and reality, makes people constantly explore ways to get rid of the limitation of time and space. The development of wireless networks and smart phones provides the possibility to solve this problem. Wireless network technology has been introduced into education, and its instruction function has given birth to mobile learning, a new way of learning. With the further development of mobile Internet technology, mobile learning extends to ubiquitous learning mode [10].

From the case of the evolution of media technology and learning style, the basic driving force of the change of learning style is the changing demands of society for learning styles. Of course, the dimension and degree of learning style change is related to the dimension and degree of demand change. However, the change in learning style needs can not directly lead to changes in learning styles. To realize this, it needs to improve media technology to create the possible environment for the desired learning style. The key to the realization of this environment is to coordinate the relationship among the learning system elements such as media technology, learners and learning objects, thus the function of media technology improved full play. For example, in this case, learners initially learn through physical production practices, which are stable in the original context. With the development of society, the amount of information accumulated has been increased quickly. Learning methods in the past are difficult to meet the present learning demand in efficiency, so that media technology are constantly improved in the dimension of efficiency and a large amount of media technology that helps learners to process information initially is integrated into instruction, making learners be free from the tedious processing of raw materials and pay more attention to the deep processing of learning objects. Media technology has changed the learning situation and provides the possibility for learners to realize the new way of learning. However, the way learners interact with media technology and learning objects has become less compatible with changes in media technology, making the function of the improved media technology difficult to play. Therefore, it is necessary to adjust the relationship between the media technology and the learner and the learning object to the learning situation after the media technology change. The pursuit of efficiency is only a dimension of society's need for learning styles and the pursuit of freedom is another kind of demand change after the demand for efficiency meets a certain level. Network technology brings the possibility of realizing the freedom of study and makes it possible to achieve mobile learning and Ubiquitous learning. The realization of this possibility needs to solve problems in other dimensions, such as learning management problems. This needs a realistic choice for relationship among learners, learning objects and media technology in the new environment created by the improved media technology on the premise of guaranteeing the full function of the improved media technology so that new learning methods are realized.

Thus it can be seen improvement of media technology does not directly lead to the change of learning style. Only when media technology improvements are driven by the need for social learning, can it be possible to bring about changes in the learning system as a result of media technology improvements, So as to promote the change of learning styles.

\section{RESEARCH CONCLUSIONS AND DISCUSSIONS}

Educational practice can not be separated from the question of how to do it. Media technology is essential for teaching systems. The role of media technology in the education system can be achieved either through integration or by means of a change instruction system. Integration makes media technology maintain the balance of the instruction system, change makes media technology break the balance of the teaching system, which either lead to the replacement of media technology, or lead to changes in the entire instruction system. Whether the replacement of media technology or changes in the entire instruction system, is it related to the needs of the teaching system changes. Only when the instruction needs change under the pressure of social change, can the instruction system play a conscious role in change. The change begins from the improvement of media technology, and then through function optimization of the media technology in the dimension and degree of instruction needs, drives the reform of other elements of instruction system, so as to make the instruction system change from the original steady state to the new steady state adapted to the social demand changes.

Based on the theory model of media technology influencing education, 3 solutions can be formed according to solving the problem of how changes in media technology can contribute effectively to educational changes.

Firstly, identify the relationship between technological change and the changing demands of society for education. In the process of introducing media technology into the educational field or improving the media technology in the field of Education, it is necessary to ask whether the introduction or improvement of media technology is aimed at the needs of education firstly. For example, according to the learning analysis techniques which have been paid more attention to at present, it is necessary to make clear what dimensions of the problems concerning imbalance between supply and demand in education it aims at solving. If technical improvement fails to find a reason for changes in the needs of the education system, this improvement will not contribute to education, even lead to interference.

Secondly, technological improvements must be consistent with the dimensions of educational change needs. If the demand is the education reform in education fairness dimension, technical improvements should be focused on 
accessibility, simplicity of operations, full coverage of resources, and accessibility et al. The degree of technological improvement needs to be matched with the change needs in the educational equity dimension.

Thirdly, based on the improved media technology, adjust the mode of use and the relationship between the elements associated with it to ensure that the improved media technology capabilities are fully exploited in practice.

\section{ACKNOWLEDGMENT}

Xiaochuan Zhu thanks prof. Meifeng Liu for her assistance in giving suggestions on the positioning of technology in education.

\section{REFERENCES}

[1] B. B. Li and X. P. Yang, "Top design and promotion mechanism of western educational change," Educational research, vol. 10, pp. 128-135, Oct. 2014.

[2] J. H. Yin, Introduction to Educational Technology, Beijing: Higher Education Press, 1996, pp. 29-31.

[3] N. Lv, The Technological Marvels of the Industrial Revolution, Beijing. Beijing University of Technology press, 2014, pp. 23-27.

[4] X. C. Zhu, "On the consistency relationship of teaching model elements," Journal of Chongqing Radio\&TV University, vol. 1, pp. 16-18, Jan 2010

[5] D. Keegan, Distance Education Foundation, Beijing: The Central Radio and Television University press, 1996, pp. 34-37.

[6] X. F. Ding, "The three generation of information technology and the three generation of Distance Education - Information technology and media teaching in Distance Education," China Distance Education, vol. 8, pp. 15-19, Aug 2000.

[7] T. H. Qv, Chinese Educational History, Wuhan: Wuhan University press, 2011, pp. 23-31.
[8] R. K. Sawyer, "The new science of learning," The Cambridge Handbook of the Learning Sciences, New York: Cambridge University Press, 2014, pp. 22-36.

[9] S. Siemsen and R. Jansen, "Connectivism and interactionism reloaded knowledge networks in the cloud," LTEC,CCIS, Switzerland: Springer International Publishing, 2014, pp. 1-12.

[10] J. Luo, "Information technology promotes learning change - From classroom learning to virtual learning, mobile learning, and ubiquitous learning," China Educational Technology, vol. 1, pp. 15-21, Jan 2014.

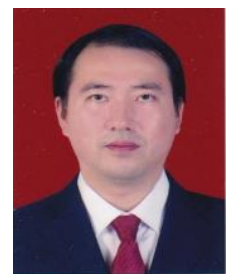

Xiaochuan Zhu was born in Chongqing city, China in 1971. In 1993, he received a bachelor's degree in audio-visual education from Southwest Normal University in Chongqing, China. In 2001, he received his master's degree in educational technology from Beijing Normal University in Beijing, China Currently, he is a doctoral candidate at educational technical college of Beijing Normal University. Three years ago, he received a professorship at Chongqing Radio\&TV University. His research focuses on education technology and distance education. He has published more than 40 papers in such professional journals as Modern distance education research and has published two books.

$\mathrm{He}$ has worked for 23 years and has experienced several different kinds of positions such as director of distance education research in Chongqing Radio and TV University et al. In these positions, he has worked as a teacher, a researcher, an administrator et al. During his work, he made a lot of research findings. For example, he has published a book named "teacher research from the perspective of relationship" (Beijing, China: The Open University of China press, 2013). His research interest is focused on distance education in the past and now it is changed to instruction design.

Prof. Zhu is a member of the center group of Education Management major in Radio and TV University, China and is also a reviewer of the Journal of Modern Distance Education research. He has won more than 20 awards for his research and was a member of the expert group on teaching mode in the personnel training model and the open education research program of the Open University of China. 